Hambrick, D. C. (2007). The field of management's devotion to theory: Too much of a good thing? Academy of Management Journal, 50, 1346-1352. https://dx.doi.org/10.5465/AMJ.2007. 28166119

Klein, K. J., \& Kozlowski, S. W. J. (Eds.) (2000). Multilevel theory, research, and methods in organizations: Foundations, extensions, and new directions. San Francisco, CA: Jossey-Bass.

McClelland, D. C. (1961). The achieving society. New York, NY: Van Nostrand.

Oh, I., Kim, S., \& Van Iddekinge, C. H. (2015). Taking it to another level: Do personality-based human capital resources matter to firm performance? Journal of Applied Psychology, 100, 935-947. http: //dx.doi.org/10.1037/a0039052

Rotolo, C. T., Church, A. H., Adler, S., Smither, J. W., Colquitt, A., Shull, A. C., ... Foster, G. (2018). Putting an end to bad talent management: A call to action for the field of I-O psychology. Industrial and Organizational Psychology: Perspectives on Science and Practice, 11(2), 176-219.

Schneider, B., \& Bartram, D. (2017). Aggregate personality and organizational competitive advantage. Journal of Occupational and Organizational Psychology, 90(4), 461-480. http://dx.doi.org/ 10.1111/joop.12180

Schneider, B., González-Romá, V., Ostroff, C., \& West, M. (2017). Organizational climate and culture: Reflections on the history of the constructs in Journal of Applied Psychology. Journal of Applied Psychology, 102, 468-482. http://dx.doi.org/10-1037/apl0000090

Schneider, B., Hanges, P. J., Smith, D. B., \& Salvaggio, A. N. (2003). Which comes first: Employee attitudes or organizational financial and market performance? Journal of Applied Psychology, 88, 836-851. http://dx.doi.org/10.1037/0021-9010.88.5.836

Schneider, B., White, S. S., \& Paul, M. C. (1998). Linking service climate and customer perceptions of service quality: Test of a causal model. Journal of Applied Psychology, 83, 150-163. http://dx.doi. org/10.1037/0021-9010.83.2.150

Schneider, B., Yost, A. B., Kropp, A., Kind, C., \& Lam, H. (2017). Workforce engagement: What it is, what drives it, and why it matters for organizational performance. Journal of Organizational Behavior. http://dx.doi.org/10.1002/job.2244

Viteles, M. (1932). Industrial psychology. New York, NY: Norton.

Xanthopoulou, D., Bakker, A. B., Demerouti, E., \& Schaufeli, W. B. (2009). Reciprocal relationships between job resources, personal resources, and work engagement. Journal of Vocational Behavior, 74, 235-244. https://doi.org/10.1016/j.jvb.2008.11.003.

\title{
What if Any Science Will Do?
}

\section{Fred Delmhorst}

Time Warner, Inc.

Rotolo et al. (2018) identify a number of reasons why the field of industrial and organizational (I-O) psychology is losing relevancy, including a lack of focus on frontier topics, which may be most relevant to talent management practitioners. As someone who subscribes to the benefits of the scientistpractitioner approach to talent management, there is nothing I hold more

Fred Delmhorst, Time Warner, Inc.

Correspondence concerning this article should be addressed to Fred Delmhorst, Time Warner, Inc., One Time Warner Center, New York, NY 10019. E-mail: fred.delmhorst@gmail.com 
precious than a healthy partnership between the I-O psychology academic community and talent management practitioners.

As such, the growing disconnect between these two worlds is of great concern. This is not a new development. As a field, I-O psychology tends to reexamine topics that have already been broadly considered in the literature, in sometimes excruciating detail and specificity. Although there may always be value to reinforcing core construct's generalizability, the risk is that emerging areas of research go untouched, such as the frontier topics outlined by Rotolo et al. Because their focus is largely on what the field of I-O psychology can and should do to remedy the increasing scientist-practitioner divide, the purpose of this commentary is to offer some additional perspective from the practitioner point of view in order to generate additional recommendations.

First, it is helpful to consider the profile of talent management practitioners, who are the buyers, or at least consumers, of the research that is produced by I-O psychologists. I would agree with Rotolo et al. that not only have some academics lost touch with practitioner's day-to-day needs, but also that practitioners are losing their connection to evidence-based research. I would propose that part of the solution to making better inroads from the I-O psychology scientific community to the talent management practitioner community is for the former to better understand the latter. Because the two communities do not often directly interact, it may come as no surprise that there is the potential for a gulf between them.

A place to start is a deeper familiarity with the core competencies that comprise the typical talent management executive who is making decisions about the strategic direction of topics such as performance management or high potential assessment. Some of these competencies include:

- Conducting organization needs assessments based on company strategy

- Persuading and influencing senior executives to sponsor talent agendas

- Securing resources, including budgets and head count

- Allocating resources and ensuring effective project management

- Gathering and presenting talent metrics

These competencies are fundamental to success as a talent management practitioner. However, they do not necessarily include an in-depth understanding of research methods, sophisticated statistics, or core I-O psychology theory. As a result, although talent management practitioners do value science, any science will do. In other words, there is an appreciation for talent management decisions being informed by relevant research. However, many practitioners, although well-intentioned, are not always equipped to differentiate between the quality of research that is available to them. 
I can recall numerous occasions in my professional career when an arbitrary statistic was cited to reinforce the case for a particular talent proposal or initiative. Regardless of the credibility of the source, I was often surprised to see that almost any data had the potential to bolster an argument and move a decision forward. The problem is that there is a wide variety of research quality from which to choose. It can be very difficult to differentiate among the choices available. There are journals that appear academic. To the casual observer, they seem to be scientific and legitimate. However, upon closer examination, one may come to find that the editorial board may be the same as the authors. These pseudoscientific resources, not surprisingly, are packaged as marketing materials to sell products and services from the same authors and editors to unwitting practitioners. Whereas the academic community would be more likely to appreciate the difference between pseudoscientific publications and legitimate, peer-reviewed periodicals (e.g., Academy of Management Journal), the average talent management practitioner may not.

Talent management professionals tend also not to be trained to differentiate between the various research designs and why some are better than others. An experimental design with strong internal validity is likely viewed no differently than a correlational study. In my experience, more often than not, what the science practitioners refer to is basic, descriptive statistics, which offer no real insights into cause and effect relationships in the workplace. At the same time, with the recent growth and popularity of people analytics and big data readily available, many companies are now able to conduct their own internal research. Although large data sets may yield high correlations, the prospect of data dredging is equally likely.

If the market is increasingly saturated with science of varying quality, and for many talent management practitioners, any science will do, then it should come as no surprise that there is confusion in the talent management field. Perhaps no better example of this is performance management. In recent years, aspects of this topic have come under rapid and constant fire. A specific example is the use of performance ratings. Seemingly from out of nowhere, a few voices proposed that performance ratings were damaging to employees and organizations and should be eliminated from the performance management cycle.

Ultimately, numerous talent management practitioners, and the organizations they serve, elected to remove ratings. In many cases, related performance processes, such as goal setting, which are rooted in fundamental I-O psychology research, were also upended. Performance management is one recent example of a popular talent management topic that was significantly influenced by voices outside I-O psychology and perhaps a missed opportunity for the I-O community to weigh in more vigorously with practitioneroriented guidance backed by decades of theory and research. 
With all of this in mind, what additional recommendations can be proposed to supplement those offered by Rotolo et al. (2018)? First, I would suggest that the I-O psychology and talent management practitioner communities jointly organize a body to help contribute to calls for papers. The idea here would be to more actively create a feedback loop that orients academia to specific topics of interest to practitioners. This would help to focus I-O psychologists on emerging frontier topics where answers to practical questions are high in demand. The People \& Strategy journal is one example where calls for papers help to identify practitioner-oriented topics such as teamwork and the digital revolution. Perhaps additional, core I-O psychology academic journals could follow suit. By understanding what is in demand by practitioners, journal review boards as well as academics would be better informed to focus their selections and avenues of research.

Second, it might be helpful to supplement the largely academic editorial review boards of many of I-O psychology's core journals with more scientistpractitioners. Industrial and Organizational Psychology: Perspectives on Science and Practice is relatively well-balanced with 15 of the 38 (40\%) editors primarily affiliated with companies while the remaining are university affiliated. However, if one were to look to other I-O psychology journals (e.g., Journal of Applied Psychology), one would find almost exclusively universityaffiliated academics. It should come as little surprise that articles selected by academics are going to be, well, academic. By diversifying the reviewers and the decision makers on top-tier I-O psychology journals with practitioners from the field, it would be more likely that research relevant to this population would land in those pages and therefore be available to the broader talent management practitioner community.

Third, there is an opportunity to better brand I-O psychology as the workplace science of choice. In their fifth recommendation, Rotolo et al. call out the need to identify new channels to reach a broader audience. This is part of the solution, but first we need to reinforce that there is a benefit to selecting I-O psychology as the workplace science of choice over other alternatives, assuming that for most practitioners, any science will do. One advantage to the more rigorous science offered by I-O psychology is stability. Rather than swinging back and forth amidst the latest talent management fads, the depth of I-O psychology science should promote the fact that, by following its insights, organizations would be less likely to change course with fundamental talent processes. Returning to the example of performance management, the wisdom of removing ratings is already being questioned by research organizations, including the Corporate Executive Board.

Fourth, and this may be somewhat controversial, but if I-O psychology is to establish itself as the workplace science of choice, perhaps the field should more actively call out the competition. In some cases, this includes 
borderline fraudulent research, whereas in others, it is simply less rigorous. At the very least, the I-O psychology community could benefit from reinforcing what good science looks like and explaining why it is a preferred choice to guide significant organization decisions and investments that impact employees' work lives on a daily basis.

Fifth, it would seem an obvious omission if the I-O community were not to be more tech friendly. In addition to generating core frameworks, as Rotolo et al. recommend, it is important to consider how we can provide real-time access to content. In this day and age, consumers of any content expect it to be at their finger tips in an instant, preferably with a seamless user interface. Once the core I-O psychology frameworks are properly packaged, it would be important to provide a digital channel to reach talent management practitioners. Mobile applications and websites that guide users in an interactive way to answers to common questions would increase the likelihood that the knowledge is put to use. I could envision an app where a talent management practitioner could select from a list of popular topics and then follow a path to more specific research-backed insights.

Although there is more work to do to reinforce I-O psychology's rightful place in talent management, there are examples where the field has hit the mark. Rotolo et al. highlight the five-factor personality model, which successfully bridged the gap from scientist to practitioner. In this and many other cases, I-O psychology has the potential to be the workplace science of choice.

\section{Reference}

Rotolo, C. T., Church, A. H., Adler, S., Smither, J. W., Colquitt, A., Shull, A. C., ... Foster, G. (2018). Putting an end to bad talent management: A call to action for the field of I-O psychology. Industrial and Organizational Psychology: Perspectives on Science and Practice, 11(2), 176-219. 